\title{
Capsule Commentary on Waitzfelder et al., Treatment Initiation for New Episodes of Depression in Primary Care Settings
}

\author{
Hale Thompson, $\mathrm{PhD}$ \\ Department of Psychiatry, Rush University Medical Center, Chicago, IL, USA.
}

J Gen Intern Med 33(8):1385

DOI: $10.1007 / \mathrm{s} 11606-018-4319-8$

(c) Society of General Internal Medicine 2018

$\mathrm{T}$ he study by Waitzfelder and colleagues provides a unique opportunity to examine factors associated with initiation of depression treatment in primary care settings across five large integrated health systems in five states. ${ }^{1}$ Leveraging electronic health record data, the findings mostly confirm documented mental health disparities. ${ }^{2}$ The odds of engaging in treatment decreased with age and income and for persons of color, who were also more likely than white patients to choose psychotherapy over antidepressant medication. Notably, the odds of initiating treatment were higher for patients who were screened with the Patient Health Questionnaire (PHQ)-9 than for those who were not.

In his seminal work, Rose's Strategy of Preventive Medicine, ${ }^{3}$ Sir Geoffrey Rose makes the case for the prevention paradox when faced with relatively common conditions like depression. This concept suggests that to achieve the greatest health benefits for the overall population, each participating individual derives only a small benefit from an intervention. Building upon the findings of Waitzfelder and colleagues in the context of this paradox, medical and epidemiological research ought to prioritize studies on the effectiveness of population-level interventions. Evidence-based collaborative care models employ a systematic use of the PHQ-9 for screening alongside focused case management, antidepressant medication management, and cognitive behavioral skillsbuilding, ${ }^{4,5}$ implementation science could aid in identifying those mechanisms that help reduce disparities across race, class, age, and gender. Qualitative inquiries with patients who are diagnosed with depression but forgo treatment may generate innovative therapies, social supports, and structural change that mitigate disparities.

The Affordable Care and Health Information Technology for Economic and Clinical Health Acts ushered in the capacity to implement population mental health strategies. The insurance mandate, mental health parity, and widespread uptake of electronic health records have expanded access to mental health care. With only $36 \%$ of newly diagnosed patients opting for treatment, ${ }^{1}$ we need to understand how best to utilize these infrastructures not only for research, but also for interventions that will systematically reduce the prevalence of depression and benefit the general population.

Corresponding Author: Hale Thompson, PhD; Department of Psychiatry Rush University Medical Center, Chicago, IL, USA (e-mail: Hale.Thompson@rush.edu).

\section{Compliance with Ethical Standards:}

Conflict of Interest: The author has no conflicts of interest with this article.

\section{REFERENCES}

1. Waitzfelder B, Stewart C, Coleman $\mathbf{K}$, et al. Treatment initiation for new episodes of depression in primary care settings. J Gen Intern Med. 2018. https://doi.org/10.1007/s11606-017-4297-2.

2. Akincigil A, Matthews E. National rates and patterns of depression screening in primary care: results from 2012 and 2013. Psychiatry Serv. 2017;(In Advance):1-7. https://doi.org/10.1176/appi.ps.201600096.

3. Rose G. Rose's Strategy of Preventive Medicine. Second. Oxford: Oxford University Press; 2008.

4. Thota AB, Sipe TA, Byard GJ, et al. Collaborative Care to Improve the Management of Depressive Disorders: A Community Guide Systematic Review and Meta-Analysis. Am J Prev Med. 2012;42(5):525-538. https:// doi.org/10.1016/j.amepre.2012.01.019.

5. Archer J, Bower P, Gilbody S, et al. Collaborative care for depression and anxiety problems. Cochrane database Syst Rev. 2012;10(10):CD006525. https://doi.org/10.1002/14651858.CD006525.pub2. 